\title{
Ichthyophonus irregularis sp. nov. from the yellowtail flounder Limanda ferruginea from the Nova Scotia shelf
}

\author{
Thomas G. Rand ${ }^{1, *}$, Kelly White ${ }^{1}$, Jamie J. Cannone ${ }^{2}$, Robin R. Gutell ${ }^{2}$, \\ Colleen A. Murphy ${ }^{3}$, Mark A. Ragan ${ }^{3,4}$ \\ ${ }^{1}$ Biology Department, Saint Mary's University, Halifax, Nova Scotia B3H 3C3, Canada \\ ${ }^{2}$ Institute for Cellular and Molecular Biology, University of Texas, Austin, Texas 78712-1095, USA \\ ${ }^{3}$ Institute for Marine Biosciences, National Research Council of Canada, 1411 Oxford St, Halifax, \\ Nova Scotia B3H 3Z1, Canada \\ ${ }^{4}$ Canadian Institute for Advanced Research, Program in Evolutionary Biology, 180 Dundas Street West, Suite 1400, \\ Toronto, Ontario M5G, 128, Canada
}

\begin{abstract}
A previously described unusual form of the protistan parasite Ichthyophonus, differing in morphological and developmental features from $l$. hoferi sensu Plehn \& Mulsow, was recovered from yellowtail flounder Limanda ferruginea Storer from the Brown's Bank area of the Nova Scotia shelf. The nuclear gene encoding the rRNA of the small ribosomal subunit was amplified from this unusual form of Ichthyophonus using the polymerase chain reaction, sequenced and aligned with other eukaryote small subunit (ssu)-rDNAs. Inferred phylogenetic trees clearly show that its ssu-rDNA is distinct from those of 2 isolates of $I$. hoferi sensu Plehn \& Mulsow from different hosts and geographical locations (herring in the North Sea, and yellowtail flounder from the Nova Scotia shelf). We consider the unusual form to be a separate species, $I$. irregularis. The occurrence of a second, distinct type of Ichthyophonus within a single host species raises the possibility that ichthyophoniasis could be produced by different (although related) pathogens, and in some cases, by concurrent infections of the two.
\end{abstract}

KEY WORDS: Ichthyophonus hoferi Ichthyophonales - Ichthyophoniasis - Limanda ferruginea Ssu-rDNA Phylogeny

\section{INTRODUCTION}

Ichthyophonus hoferi Plehn \& Mulsow (1911) causes systemic infections in at least 80 species of teleost fish from marine, estuarine and freshwater habitats in both temperate and tropical regions worldwide. Moreover, organisms identified as $I$. hoferi have been reported as pathogens of elasmobranch fishes, marine and freshwater crustaceans, amphibians, reptiles, and piscivorous birds (for extensive references see Rand 1990, 1994).

Ichthyophonus hoferi has often been referred to as a fungus, as its morphological and developmental features are reminiscent of those associated with some

•E-mail: thomas.rand@stmarys.ca fungal taxa (see Johnson \& Sparrow 1961, Neish \& Hughes 1980, Alderman 1982, Rand 1990).

More-detailed analysis of the primary literature reveals extensive variability among the morphological, life-history and developmental characters reported for organisms identified as Ichthyophonus hoferi from and for clinical and histopathological features of the associated pathologies in different host fish species (Rand 1990). Some of these reported differences probably arise from features specific to different hosts or host tissues (see Rand 1990). However, sufficient doubts have remained to convince some authorities (Johnson \& Sparrow 1961, MacKenzie 1979, Neish \& Hughes 1980 , Alderman 1982, Lauckner 1984, Rand 1990) that $I$. hoferi as currently delineated could, at least in principle, refer to a complex of 2 or more species. 
Rand (1994) took this a step farther by recovering 2 forms of Ichthyophonus from yellowtail flounder Limanda ferruginea collected on the Nova Scotia shelf. These forms differed in their cell wall profiles, intensity of thallus wall staining by Alcain blue CEC, abilities to germinate in vitro without a seawater overlay, morphology of the vegetative thallus, penetration of mycelia into the culture medium, and time-course and nature of spore production in culture. One form was readily referable to Ichthyophonus hoferi sensu Plehn \& Mulsow (1911), whereas the other was more similar to the 'I. hoferi' observed by Hendricks (1972) from $L$. ferruginea and the longhorn sculpin Myxocephalus octodecemspinosus, and by Gartner \& Zwerner (1988) from Bean's blueback Scopelogadus beanii. Because Plehn \& Mulsow (1911) had been less than clear in their original definition of $I$. hoferi, Rand (1994, p. 27) proposed that detailed analytical taxonomic approaches involving life-cycle and ultrastructural studies, and direct-sequence-analysis of DNA and RNA molecules from these various pathogens considered to be $I$. hoferi be undertaken before a new species is claimed'.

Interest in molecular-sequence analysis of possible additional species of Ichthyophonus was heightened by the report (Ragan et al. 1996), based on analysis of its small subunit (ssu)-rDNA sequence, that $I$. hoferi sensu Plehn \& Mulsow (1911) isolated from Limanda ferruginea is not a fungus. It belongs instead to a novel clade of protistan parasites related to both animals and fungi (and perhaps more closely to animals). Other members of this clade were parasites of various aquatic animals, including fish, and all had been considered to be of uncertain taxonomic position. On this basis, Cavalier-Smith (1998) assigned these organisms to the new taxon Ichthyosporea, according it Class status. Spanggaard et al. (1996) reported that I. hoferi sensu Plehn \& Mulsow (1911) isolated from the herring Clupea harengus likewise was related not to fungi, but to the rosette agent of salmon (which according to Ragan et al. 1996 is also a member of Ichthyosporea). Since then, other organisms assignable to Ichthyosporea, based on analysis of their ssurDNA sequences, have been recovered from aquatic environments. Thus, molecular-sequence characterization of this possible new form of Ichthyophonus would not only clarify the origin of an important systemic disease of fish, but could expand our understanding of organismal diversity within a new and strategically placed taxon of eukaryotic life.

Herein we report the nuclear ssu-rDNA sequence from the distinctive form of Ichthyophonus observed by Rand $(1990,1994)$, and we discuss the implications for our understanding of the causes of ichthyophoniasis, and for relationships within Ichthyosporea.

\section{METHODS AND MATERIALS}

A total of 222 yellowtail flounder Limanda ferruginea was collected in March 1997 during a groundfish survey of Nova Scotia shelf on the Canadian Fisheries research trawler 'Alfred Needler'. All fish landed during the cruise were captured in a Western IIA bottom trawl with a $2 \mathrm{~cm}$ cod end liner towed for $30 \mathrm{~min}$ at each fishing station. The body and pericardial cavity of each fish was opened and the fresh viscera inspected macroscopically for lesions considered characteristic of ichthyophoniasis in yellowtail flounder (Rand 1994) as soon after capture as possible (usually within $4 \mathrm{~h}$ ).

Fish considered likely to be infected with Ichthyophonus were frozen at $-40^{\circ} \mathrm{C}$ in toto and taken to the laboratory for further study. Infected tissues were excised, prepared as wet mounts for microscopic confirmation of the presence of Ichthyophonus, and if positive plunged into liquid nitrogen prior to DNA extraction. Ten thalli were excised from infected kidney and liver tissue of 2 fish, placed into PBS buffer (Sambrook et al. 1989) and washed 3 times with PBS to remove residual host tissue. Thalli were then crushed by vigorous grinding in microcentrifuge tubes at $-196^{\circ} \mathrm{C}$. DNA was extracted using the Puregene kit (Gentra), sonicated $(3 \times 10 \mathrm{~s})$, then incubated first with Proteinase $\mathrm{K}$ $\left(20 \mathrm{mg} \mathrm{ml}{ }^{-1}, 55^{\circ} \mathrm{C}, 3 \mathrm{~h}\right.$ ) and thereafter with RNase $A$ $\left(37^{\circ} \mathrm{C}, 30 \mathrm{~min}\right)$. DNA was purified by standard phenolchloroform extraction and ethanol precipitation, dried, and re-suspended in TE buffer (Sambrook et al. 1989). ssu-rDNAs were PCR-amplified using the GeneAmp XL PCR kit (Perkin Elmer BioSystems) using universal eukaryotic oligonucleotide primers $\left(\mathrm{GO}_{1}\right.$ and $\mathrm{GO}_{7}$ : Saunders \& Kraft 1994). Thirty amplification cycles were carried out $\left(96^{\circ} \mathrm{C}\right.$ for $30 \mathrm{~s}, 65^{\circ} \mathrm{C}$ for $30 \mathrm{~s}, 72^{\circ} \mathrm{C}$ for 1 min; PEC 9600 cycler). The amplicon (ca 1850 bp) was PCR-sequenced directly (Perkin Elmer BioSystems' BigDye terminator chemistry) on an ABI 377 automated sequencer.

The resulting ssu-rDNA sequence, which preliminary BLASTN analysis showed was highly similar to that of Ichthyophonus hoferi sensu Plehn \& Mulsow (1911), was aligned in stages against the eukaryotic ssu-rDNA database. Using the alignment editor AE2 (Maidak et al. 1997), the sequence was first juxtaposed manually with the most similar sequences already in the alignment database so as to maximize sequence similarity. Then, positions with significiant covariations and within potential secondary-structural helices were adjusted so as to maintain base-pairing in the secondary-structure model (reviewed by Gutell et al. 1994). From the resulting alignment we selected a subset of 49 ssu-rDNAs, including that of the presumed Ichthyophonus from this study, representing phyletically diverse animals, fungi, green plants and green 
algae, red algae, acanthamoebae and apicomplexa (see Fig. 1). The ssu-rDNA sequence reported for Sphaerosoma arcticum (GenBank Y16260.2) includes several regions of ambiguous data represented as N's, where these aligned with nucleotides in ssu-rDNAs from other organisms (particularly other members of Ichthyosporea), these ambiguous regions were left as N's, whereas when they aligned with gaps in most other ssu-rDNAs (particularly from Ichthyosporea) they were represented as gaps (i.e., '-'). Removal of structural annotations, and empty and sparsely populated columns, yielded a $49 \times 1823$ matrix on which the results presented herein are based. A further 383 columns corresponding to nucleotides present in only a few species and regions typically associated with sizevariation of loops were further deleted to yield a moreconservative $49 \times 1440$ matrix. In trees inferred from the latter, several clades (e.g., fungi, acanthamoebae) considered on the basis of overwhelming external evidence to be monophyletic were sometimes broken up, or received only weak bootstrap support; this was taken as evidence that an unacceptable amount of phylogenetic signal had been lost in the construction of this matrix.

Inference of trees was carried out using programs within version 3.53 of the PHYLIP package (Felsenstein 1989) on a Sun Enterprise 4001 server under UNIX. Maximum-likelihood inference was performed using DNAML with global optimization and assuming a transition-to-transversion ratio of 2.00. Parsimony trees were inferred using DNAPARS, with global optimization and 1000 separately nucleated searches for the shortest tree. Parsimony analysis was bootstrapped using SEQBOOT, DNAPARS and CONSENSE. The neighbor-joining tree was generated using DNADIST (assuming Felsenstein's ML model) and NEIGHBOR. The order of sequence addition was randomized (jumbled) in all analyses.

The holotype (DAOM 216137) and representative slides (DAOM 216138) of this new form of Ichthyophonus have been deposited in the National Fungal Collection, William Saunders Building, Agriculture Canada, Ottawa K1A 0C8, Canada. Representative material has also been archived in one of our laboratories (that of T.G.R.). The ssu-rDNA sequence of this organism has been deposited in GenBank under the accession number AF232303.

\section{RESULTS AND DISCUSSION}

Of the 222 yellowtail flounder collected from the Nova Scotian Shelf, 7 of $47(15 \%)$ yellowtail flounder from Brown's Bank $\left(42^{\circ} 50^{\prime} \mathrm{N}, 65^{\circ} 40^{\prime} \mathrm{W}\right)$ were infected by the unusual form of Ichthyophonus. All of these were captured in the southwestern region of Brown's Bank. Nine of the other $175(0.5 \%)$ yellowtail flounder from the Nova Scotian shelf, and 2 from Brown's Bank, were infected with $I$. hoferi sensu Plehn \& Mulsow (1911). Co-infections with both 1 . hoferi sensu Plehn \& Mulsow and the unusual form of Ichthyophonus were not observed in these collections, although one of us (T.G.R.) has observed such co-infections on other accasions.

An apparently single amplicon corresponding in mobility to an intron-free nuclear rDNA was generated by PCR and sequenced directly, yielding (as would be expected if only 1 ssu-rDNA had been amplified) clean chromatograms not detectably complicated by background signals. The sequence, which showed highest BLASTN scores against the 2 Ichthyophonus hofer sequences already in GenBank (scores 3303 and 2940 against U25637 from Limanda ferruginea and U43712 from Clupea harengus, respectively), was readily aligned on the basis of sequence similarity and predicted secondary structure against the eukaryotic alignment ssu-rRNA database. The eukaryotic ssurDNA alignment is stable and highly refined, having undergone more than $15 \mathrm{yr}$ of analysis, evaluation and refinement (Gutell 1999).

Pairwise identity between the new sequence and U25637, the Ichthyophonus hoferi ssu-rDNA reported by Ragan et al. (1996), is 1723/1751 nucleotides (98.4\%) exclusive of gaps ( 2 gapped positions, $0.1 \%$ ) and the $5^{\prime}$ and 3 ' terminal regions of primer annealing. Pairwise identity values vis-à-vis U43712, the $I$. hoferi ssu-rDNA reported by Spanggaard et al. (1996), are more complicated, as the latter sequence lacks a fur ther 28 nucleotides at the $5^{\prime}$ end, and 11 at the $3^{\prime}$ end, inside the regions of primer annealing, and moreover contains a few regions of apparently poor sequence resolution in which ambiguously assigned nucleotides (N's) and some unexpected short gaps are found. We estimate the pairwise identity between the Ichthyophonus ssu-rDNA reported herein and U43712 to be about $1683 / 1718(98.0 \%)$ if all 6 ambiguously assigned nucleotides are resolved as identities. These values are not significantly different than that between the $2 I$. hoferi ssu-rDNAs (1691/1722 nucleotides, or $98.2 \%$, if ambiguities in U43712 are resolved as identities, or slightly greater if some gaps are assumed to be artifacts of poor sequence resolution).

After removal of alignment regions that do not contribute information about common ancestry, phylogenetic trees were inferred by maximum likelihood, parsimony and neighbor-joining. In all analyses, the ssu-rDNA of the unusual form of Ichthyophonus formed a sister lineage to the $2 I$. hoferi ssu-rDNAs (Ragan et al. 1996, Spanggaard et al. 1996). In parsimony analysis of the more-inclusive (1840-position) 


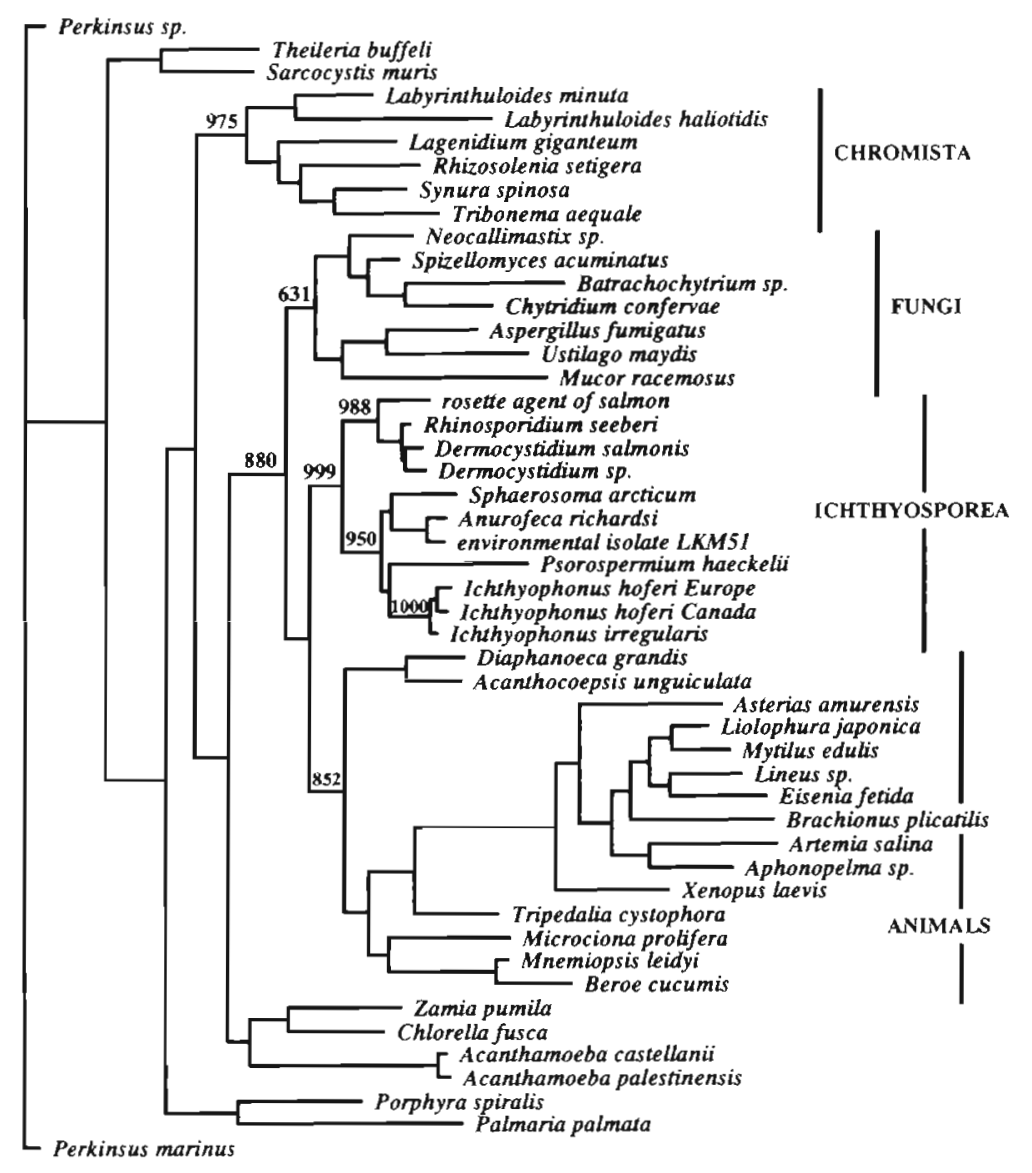

Fig. 1. Ssu-rDNA tree showing position of the 'unusual' form of Ichthyophonus, recognized herein as a new species, I. irregularis. The ssurDNA of Perkinsus marinus was set as outgroup, based on previous results (Ragan et al. 1996). The tree shows the globally optimized maximally likely relationship among 49 selected ssu-rDNAs, based on 1840 stably aligned positions at a transition/transversion ratio of 2.00 (see 'Methods and materials'). One rate class of sites was assumed. Bootstrap replicate values (shown above and to the left of selected nodes) were generated by parsimony analysis with $\mathrm{n}=1000$ replicates. GenBank accession numbers for ssu-rDNA sequences in the tree, from top: Perkinsus sp. L07375; apicomplexa Z15106, M64244: chromista L27634, U21338, M54939, M87329, M87336, M55286; fungi M59761, M59759, AF051932, M59758, M60300, X62396, X54863; ichthyosporea L29455, AF118851, U21337, U21336, Y16260, AF070445, AJ 130859, U33180, U43712, U25637, AF232303; animals L10824, L10823, D14358, X70210, L24489, X79878, X79872, U29235, X01723, X13457, X04025, L10829, L10825, L10826, D15068; green plants M20017. X74002; slime molds U07413, U07411; red algae L26177, Z14142; P. marinus $\times 75762$

matrix, bootstrap support for the clade of the 3 Ichthyophonus ssu-rDNAs is $1000 / 1000$, and for the $2 I$. hoferi sequences 953/1000 (Fig. 1). The corresponding bootstrap values for these clades based on the less-informative (1440-position) matrix are 999.5/1000 and $891 / 1000$. These results are consistent with considering the unusual form to be an Ichthyophonus distinct from I. hoferi sensu Plehn \& Mulsow (1911).
The Ichthyosporea clade (also called Mesomycetozoa) was observed in all analyses based on either matrix. In parsimony analysis of the more-inclusive matrix, bootstrap support for this clade was 999/1000 (Fig. 1). Two well-supported subgroups were apparent within this clade, one comprising ssu-rDNAs of the 2 Dermocystidium isolates, Rhinosporidium seeberi and the rosette agent of salmon, the other comprising the remaining 7 sequences including those from Ichthyophonus. Within the latter subgroup, the ssu-rDNAs from an aquatic environmental isolate, Anurofeca richardsi (formerly Prototheca richardsi) and Sphaerosoma arcticum consistently grouped together, as did the 3 Ichthyophonus ssu-rDNAs. The branching position of the ssu-rDNA of Psorospermium haeckelii, however, was resolved differently within this subgroup, depending, e.g., on alignment matrix, inference method and transition/transversion ratio. In parsimony analysis of the less-informative matrix, bootstrap support for Ichthyosporea fell to $663 / 1000$, as resolution in this area of the tree was greatly degraded; however, bootstrap support for the 2 subgroups of Ichthyosporea (above) increased to $991 / 1000$ and $997 / 1000$ respectively (compare Fig. 1).

No simple relationship exists between a phylogenetic tree and hierarchical classification. Thus although the ssu-rDNA tree (Fig. 1) is compatible with a genus Ichthyophonus (organisms corresponding to the 3 Ichthyophonus sequences) and a more closely delimited species I. hoferi the Canadian and European I. hoferi ssurDNAs), the taxonomic status of the new Ichthyophonus cannot be deduced automatically from the ssu-rDNA tree alone, but must be argued on the specific merits of the case.

Rand (1994) presented an extensive comparison of spore and thallus sizes, histochemical and light-polarizing profiles of resting-spore walls, and developmental features of thalli and spores of Ichthyophonus hoferi sensu Plehn \& Mulsow (1911) vis-à-vis the 'unusual' form of Ichthyophonus whose ssu-rDNA is reported herein. Of the 46 characters considered, the 2 forms were qualitatively different in 3, quantitatively different in 6 , and similar or identical in 30 ; no comparison was possible with respect to the remaining 7 characters. The quali- 
tatively different characters were wall profile of the thallus (smooth for $I$. hoferi sensu Plehn \& Mulsow, rough and irregular for the unusual form), germination without seawater overlay (observed and not observed, respectively), and penetration of mycelia into the culture medium (observed and not observed, respectively). The 2 forms differed clearly with respect to their staining profiles with Alcain blue CEC (for carbohydrates) and Ninhydrin-Schiff (for proteins). Moreover, pathological features associated with the infections caused by both forms also differed (Rand 1990, 1994). Lastly, geographical distributions of both forms within the Nova Scotia shelf area also differed considerably (see Rand 1990). In yellowtail flounder, the unusual form apparently is restricted to the Brown's Bank area, while I. hoferi sensu Plehn \& Mulsow (1911) is more widely distributed (Rand 1992). Although concluding that it was 'tempting to establish this unusual form of Ichthyophonus hoferi as a new species of Ichthyophonus', Rand (1994) pointed to the lack of clarity in the original delineation of $I$. hoferi (Plehn \& Mulsow 1911). He recommended that further data, particularly ultrastructural and molecular, be obtained on both forms before any revision is undertaken.

Sequences of the nuclear gene encoding ssu-rRNA have repeatedly proven useful in the identification and assignment to taxa of organisms deficient in unambiguous phenetic characters. Ragan et al. (1996) reported the nuclear ssu-rDNA sequence of Ichthyophonus hoferi sensu Plehn \& Mulsow (1911) from yellowtail flounder Limanda ferrugenea collected on the Nova Scotia Shelf, and Spanggaard et al. (1996) reported the sequence of $I$. hoferi sensu Plehn \& Mulsow (1911) from herring collected in the North Sea. The latter authors also noted that an identical ssu-rDNA sequence was obtained from $I$. hoferi recovered from rainbow trout, apparently from Japan. These sequences are more than $98 \%$ identical with each other and, more importantly, group together stably to the exclusion of the ssu-rDNA from the 'unusual' Ichthyophonus (above and Fig. 1). As yellowtail flounder and herring are members of very divergent orders of teleosts, these data strongly suggest that, despite the difference in hosts, the causative organism in each case can be referred to the same genus, I. hoferi sensu Plehn \& Mulsow (1911).

Although in pairwise comparisons the ssu-rDNA of the 'unusual' Ichthyophonus isolate is approximately as dissimilar from either of the $2 I$. hoferi ssu-rDNAs as they are from each other; the pattern of differences (more precisely, of synapomorphies) clearly distinguishes the Ichthyophonus ssu-rDNA from that found in the $2 I$. hoferi isolates. As noted above, this distinctiveness enjoys strong bootstrap support in parsimony analysis, is observed with 3 different approaches to tree inference, and is not strongly dependent on whether or not the sparser or more ambiguously aligned positions are included in the analysis. This is despite the fact that the 'unusual' Ichthyophonus was recovered from the same host species (Limanda ferruginea) and in the same geographical area (Brown's Bank, on the Nova Scotia shelf) as the I. hoferi studied by Ragan et al. (1996). Added to the morphological. histochemical, physical and developmental differences presented by Rand (1994), we consider the evidence sufficient to justify recognition of the 'unusual' form of Ichthyophonus as a separate species, for which we propose the name I. irregularis in recognition of the irregular profile of the outer surface of the wall of the coralloid thallus.

The occurrence of a second, distinct type of Ichthyophonus within a single host species raises the possibility that ichthyophonaisis could be produced by different (although related) pathogens, and in some cases, by concurrent infections of the two. Sproston (1944) described and illustrated morphological forms of Ichthyophonus from mackerel that are similar to the 2 forms we have recovered from the Nova Scotia shelf. T.G.R. (unpubl. data) has also recovered yellowtail flounder from the Brown's Bank infected concurrently with both forms of Ichthyophonus. These results also illustrate the likelihood that there is further, as yet, unidentified biodiversity within class Ichthyosporea.

While the new ssu-rDNA trees (Fig. 1 and results not shown) further solidify the position of Ichthyosporea within the clade of Animals plus Fungi as previously proposed by Ragan et al. (1996), they do not resolve the question of whether Ichthyosporea is the deepest branch on the line leading to animals or, alternatively, the deepest branch on the line leading to fungi. A position as the sister-group to Animals plus Fungi seems less likely, but cannot be ruled out. Again, ultrastructural data, and sequence analyses of additional genes, are urgently required.

Acknowledgements. We gratefully acknowledge support of an NSERC operating grant (T.G.R.), US National Institutes of Health grant GM48207 (R.R.G.), and the National Research Council of Canada (M.A.R.). M.A.R. additionally thanks the Canadian Institute for Advanced Research, Program in Evolutionary Biology for support. Issued as NRCC 42317

\section{LITERATURE CITED}

Alderman DJ (1982) Fungal diseases of aquatic animals. In Roberts RJ (ed) Microbial diseases of fish. Academic Press, London, p 189-242

Cavalier-Smith T (1998) Neomonada and the origin of animals and fungi. In: Coombs GH, Vickerman K, Sleigh MA, Warren $A$ (eds) Evolutionary relationships among protozoa. Chapman \& Hall, London, p 375-407

Felsenstein J (1989) PHYLIP - Phylogeny inference package Cladistics 5:164-166 
Gartner JV Jr, Zwerner DE (1988) An Ichthyophonus-type fungus in the deep-sea pelagic fish Scopelogadus beanii (Gunther) (Pisces: Melamphaidae): pathology, geographical distribution and ecological implications. J Fish Biol 32 $459-470$

Gutell RR (1999) Comparative analysis of RNA sequences Symposium on RNA biology, Nucleic Acids Res Symp Ser $41: 48-53$

Gutell RR, Larsen N, Woese CR (1994) Lessons from an evolving ribosomal RNA: $16 \mathrm{~S}$ and 23S rRNA structure from a comparative perspective. Microbiol Rev 58:10-26

Hendricks JD (1972) Two new host species for the parasitic fungus Ichthyophonus hoferi in the Northwest Atlantic. J Fish Res Board Can 29:1776-1777

Johnson TW Jr, Sparrow FK Jr (1961) Fungi in oceans and estuaries. Cramer, Weinheim

Lauckner $G$ (1984) Diseases caused by microorganisms. Agents: fungi. In: Kinne $O$ (ed) Diseases of marine animals, Vol IV, Pt 1. Biologische Anstalt Helgoland, Hamburg, p $89-113$

MacKenzie K (1979) Some parasites and diseases of blue whiting Micromesistius poutassou (Rissou) to the north and west of Scotland and at the Faroe Islands. Scott Fish Res Rep 17:1-14

Maidak BL, Olsen GJ, Larsen N, Overbeek R, McCaughey MJ, Woese CR (1997) The RDP (Ribosomal Database Project). Nucleic Acids Res 25:109-111

Neish GA, Hughes GC (1980) Fungal diseases of fishes. Book 6. In: Snieszko SF, Alexrod HR (eds) Diseases of fishes. TFH Publications, Neptune, NJ, p 61-100

Plehn M. Mulsow K (1911) Der Erreger der Taumelkrankheit der Salmoniden. Zentbl Bakteriol Parasitenkd Infekt-

Editorial responsibility: David Bruno,

Aberdeen, Scotiand, UK krankh Hyg Orig 59:63-68

Ragan MA, Goggin CL, Cawthorn RJ, Cerenius L, Jamieson AVD, Plourde SM, Rand TG, Söderhäll K, Gutell RR (1996) A novel clade of protistan parasites near the animal-fungal divergence. Proc Natl Acad Sci USA 93:11907-11912

Rand TG (1990) Studies on the biology of Ichthyophonus hoferi Plehn and Mulsow, 1911 from Nova Scotian yellowtail flounder, Limanda ferruginea (Storer). PhD thesis, Univ. New Brunswick, Fredericton

Rand TG (1992) Seasonal and geographical distribution of Ichthyophonus hoferi Plehn and Mulsow, 1911 in yellowtail flounder, Limanda ferruginea on the Nova Scotia shelf, Canada. J Mar Biol Assoc UK 72:669-674

Rand TG (1994) An unusual form of Ichthyophonus hoferi (Ichthyophonales: Ichthyophonaceae) from yellowtail flounder Limanda ferruginea from the Nova Scotia shelf. Dis Aquat Org 18:21-28

Sambrook J, Fritsch EF, Maniatis T (1989) Molecular cloning. A laboratory manual 2nd edn. Cold Spring Harbor Laboratory Press, Cold Spring Harbor, NY

Saunders GW, Kraft GT (1994) Small-subunit rRNA gene sequences from representatives of selected families of the Gigartinales and Rhodymeniales (Rhodophyta). 1. Evidence for the Plocamiales ord. nov. Can J Bot 72: $1250-1263$

Spanggaard B, Skouboe P, Rossen L, Taylor JW (1996) Phylogenetic relationships of the intercellular fish pathogen Ichthyophonus hoferi and fungi, choanoflagellates and the rosette agent. Mar Biol 126:109-115

Sproston NG (1944) Ichthyosporidium hoferi (Plehn \& Mulsow, 1911), an internal fungoid parasite of the mackerel J Mar Biol Assoc UK 26:72-98

Submitted: October 26, 1999; Accepted: March 6, 2000 Proofs received from author(s): May 15, 2000 